\title{
Petrous Meningiomas: A Review of Seventeen Cases
}

\author{
R.L. Macdonald, P.J. Muller, W.S. Tucker, R.J. Moulton and A.R. Hudson
}

\begin{abstract}
Seventeen patients with petrous meningiomas managed at St. Michael's Hospital, during the years 1973-1987, were retrospectively reviewed. There were 15 females and 2 males; their ages ranged from 42 to 68 years (mean age: 53 years). The clinical presentation most commonly included headache and eighth cranial nerve dysfunction; the average duration of symptoms was 6 years ( 3 month - 27 years). Computed tomography was performed in 15 cases. The mean tumour size was 2.5 centimeters $(0.5-4 \mathrm{~cm})$. The most common site of tumour origin was at or medial to the porus acousticus. Meningioma was suspected preoperatively in 10 of the 15 patients who had preoperative CT scans. Complete excision was obtained in 12 cases. There were no operative deaths after initial resections. Postoperative morbidity included worsening of pre-existing hearing loss in six patients, transient facial nerve palsies in six, permanent facial nerve palsies in four and new facial or corneal hypesthesia in three. Two patients developed cerebrospinal fluid fistulae. Tumour recurrence occurred into two patients in whom a complete resection was anticipated. Also, in two patients with incompletely resected tumours second operations were required. Fourteen patients are alive, 13 of whom care for themselves independently. The average follow-up was 5 years ( 6 months - 9 years). It seems appropriate to recommend initial radical surgical excision of these benign tumours, where possible, in order to prevent tumour recurrence.
\end{abstract}

RÉSUMÉ: Méningiome pétreux: revue de dix-sept cas Nous faisons une révision rétrospective de 17 cas de méningiome pétreux traités à l'Hôpital St-Michael de 1973 à 1987. Le groupe est composé de 15 femmes et 2 hommes, âgés de 42 à 68 ans (âge moyen: 53 ans). La présentation clinique incluait le lpus fréquemment de la céphalée et une dysfonction du huitiéme nerf crânien; la durée moyenne des symptômes était de 6 ans (de 3 mois à 27 ans). On a procédé à une tomodensitométrie chez 15 cas. La taille moyenne de la tumeur était de 2.5 centimètres (de 0.5 à $4 \mathrm{cms}$ ). Le site d'origine le plus fréquent était au niveau de l'orifice du conduit auditif interne ou en position plus médiane. En préopératoire on a soupçonné la présence d'un méningiome chez 10 des 15 patients qui ont eu un CT scan. L'excision a été totale chez 12 cas. Il n'y a eu aucun décès opératoire lors de la résection initiale. La morbidité postopératoire a été la suivante; une aggravation de la perte de l'acuité auditive pré-existante chez six patients, une paralysie transitoire du nerf facial chez six, une paralysie permanente du nerf facial chez quatre et une hyperesthésie faciale ou cornéenne chez trois. Deux patients ont développé des fistules entraînant un écoulement de liquide céphalo-rachidien. Une récidive de la tumeur est survenue chez deux patients chez qui on croyait avoir procédé à une résection complète. De plus, une seconde intervention a été nécessaire chez deux patients chez qui la résection avait été incomplète. Quatorze patients sont vivants, dont 13 peuvent subvenir eux-mêmes à leurs besoins. Le suivi moyen était de 5 ans (de 6 mois à 9 ans). 11 semble pertinent de recommander l'excision radicale de ces tumeurs bénignes, lors de la chirurgie initiale si possible, afin de prévenir une récidive de la tumeure.

Can. J. Neurol. Sci. 1990; 15:399-403

Posterior fossa meningiomas, especially those arising from the posterior aspect of the petrous bone, present a major challenge to neurosurgeons because of their close proximity to critical neurovascular structures. Postoperative mortality after resection of petrous meningiomas has been as high as $40 \% .^{1-4}$ Complete resections have only recently been possible with acceptable morbidity and mortality.5.6 An additional problem with these lesions is tumour recurrence in the face of presumed total resection, a phenomenon not encountered with the more common lesion in this region, the acoustic neuroma, which when totally removed do not recur. ${ }^{7,8,5}$ We present our experiences in the management of 17 patients with petrous meningiomas.

\section{Materials and Methods}

Seventeen patients had petrous meningiomas resected at St. Michael's Hospital, University of Toronto, between 1973 and 1987. There were 15 females and two males, ranging in age from 42 to 68 years (mean age: 53 years).

\section{Clinical Features}

In 8 of 17 patients the initial symptom was unilateral hearing loss with or without tinnitus; a further 3 patients presented with disequilibrium. Localized pain over the mastoid area of the appropriate side was identified in 5 cases. The initial symptom 
in two patients was trigeminal neuralgia. The mean duration of symptoms was 6 years (range 3 months - 27 years). Neurological examination disclosed unilateral trigeminal and/or the vestibulocochlear nerve malfunction in 15 of 17 cases. Five patients also had cerebellar signs - 3 with gait ataxia and 2 with limb ataxia. Two patients with small tumours located on the lateral portion of the petrous temporal bone were neurologically intact. Only one patient had papilledema.

\section{Preoperative Neuroradiology and Audiometry}

Of eight patients who had plain skull films none had abnormal petrous views. Bony erosion of the petrous apex was identified in one of six patients with petrous tomograms. Fifteen patients had thin cut axial CT scans and all were abnormal (Table 1). Air cisternography was used to delineate suspicious areas in two cases. The long diameter of the tumours was 0.5 to $4 \mathrm{~cm}$ (mean $2.5 \mathrm{~cm}$ ). Two small intracanalicular tumours were the only tumours associated with bony abnormalities of the internal auditory meatus on CT scan. Adjacent bony erosion was seen on the CT scan in two other cases. All tumours were hyperdense on contrast enhanced CT scanning; four had focal areas of calcification. In 8 cases tumours extended into the clival and/or supratentorial areas. This was an important feature in that only patients with such tumours were incompletely resected. In general the lack of bony changes and the CT appearance led to a correct preoperative diagnosis of meningioma in 10 to 15 cases.

Table 1: CT Scan Features in 15 Patients with Petrous Meningiomas

\begin{tabular}{ll}
\hline Feature & Number of Patients \\
\hline Size & \\
intracanalicular $(<1.5 \mathrm{~cm})$ & 2 \\
$1.5-2.5 \mathrm{~cm}$ & 3 \\
$>2.5 \mathrm{~cm}$ & 8 \\
unknown & 2 \\
Cilcification & 4 \\
Bony changes & 2 \\
flared porus acousticus & 2 \\
bony erosion & 1 \\
unknown & 1 \\
Tumour Extension & \\
tentorial & 6 \\
clival & 4 \\
Hydrocephalus & 2 \\
\hline
\end{tabular}

Cerebral angiography revealed a tumour blush in 7 of 11 patients (Figure 2). The arterial blood supply to the tumour included branches from meningohypophyseal trunk, the ascending pharyngeal artery or middle meningeal artery. Figures $I$ and 2 show typical radiological features of petrous meningiomas.

Preoperative audiometry and BAER were performed in eight patients. A delayed wave five on BAER was identified in 7 cases. Standard audiometry was abnormal in two of eight patients.

\section{Tumour Pathology}

The histological patterns were transitional and syncytial. There were no tumours with angioblastic or malignant histology. The lesions arose in the vicinity of the internal auditory meatus, jugular foramen or along the borders of the dural venous sinuses.

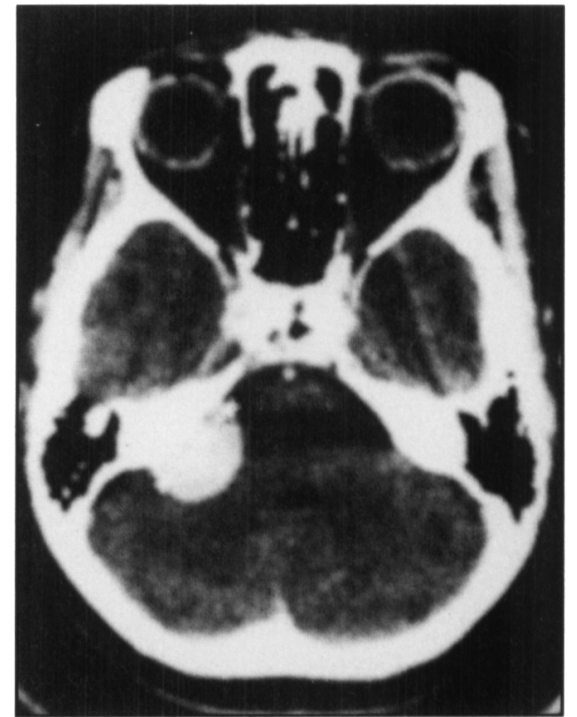

Figure I - Enhanced axial CT scan demonstrating a $2.5 \mathrm{~cm}$ diameter lesion with the typical features of a petrous meningioma - bright enhancement, broad dural base location not precisely at the porus acousticus and absence of bony changes of the internal auditory meatus and petrous bone.

\section{Operative Management}

All patients had perioperative steroid coverage. Two patients managed early in the series were operated upon in the sitting position; the remainder were placed in the park bench position. A lateral suboccipital craniectomy was utilized in all cases and was combined with a subtemporal craniotomy at the same or subsequent operation for resection of supratentorial tumour extension in three cases. The lateral cerebellomedullary cistern and cisterna magna were opened to facilitate CSF drainage. Despite this, resection of cerebellar tissue was required in two cases because of intraoperative cerebellar swelling. After cerebellar retraction and cranial nerve identification the tumour was removed piecemeal by various techniques including bipolar coagulation, suction and ultrasonic aspiration. After completing the tumour removal, the dural origin was thoroughly coagulated.

\section{Results}

Complete resection was obtained in 12 cases; we were unable to determine the extent of resection in one case. There were no operative deaths after first surgery. Postoperative morbidity included worsening of pre-existing hearing loss in six patients, transient facial nerve palsy in six and permanent facial nerve palsy in four (Table 2). Three patients suffered new facial and corneal hypesthesia and two patients developed CSF fistulae, one of whom required a ventriculoperitoneal shunt. No patient who had normal hearing preoperatively developed postoperative hearing difficulty. Four patients required tarsorrhaphy for corneal protection and another underwent tracheostomy as a result of pulmonary complications. Transient unilateral cerebellar signs were commonly seen postoperatively. Two patients required delayed CSF shunting procedures for communicating hydrocephalus.

The mean duration of follow-up was 5 years $(6$ months 9 years). We classified outcome as good if the patient returned to domestic work or commercial employment, fair if the patient 

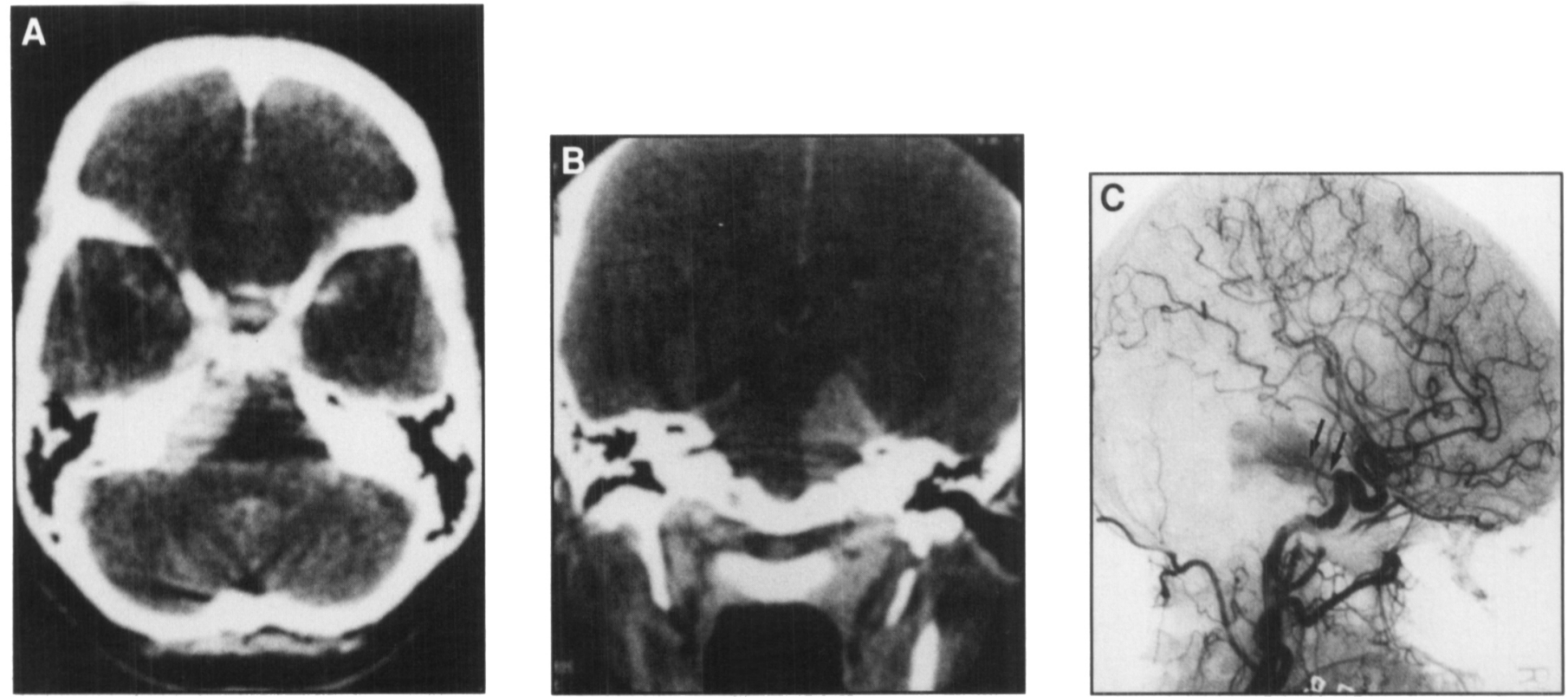

Figure 2 - Enhanced axial (a) and coronal (b) CT scans showing a petrous meningioma arising along the medial petrous ridge and extending superiorly through the tentorial incisura. Lateral subtraction angiogram (c) of an internal carotid artery injection demonstrating a tumour blush with supply from an enlarged meningohypophyseal trunk (arrows).

Table 2: Postoperative Morbidity in 17 Cases of Petrous Meningioma

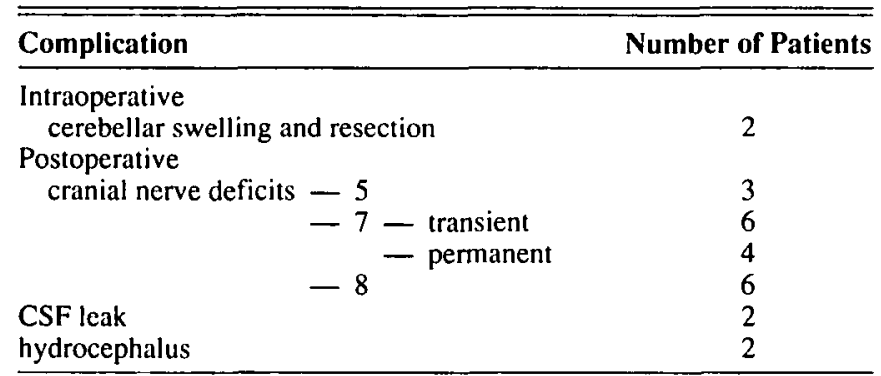

was independent but unable to work and poor if the patient required assistance with activities of daily living. Thirteen of seventeen patients had a good result and $4 / 17$ a fair result after first surgery (Table 3).

Table 3: Follow-up Data in 17 Patients with Petrous Meningioma

\begin{tabular}{lcc}
\hline \hline Outcome & \multicolumn{2}{c}{ Number of Patients } \\
\hline total & $\begin{array}{c}\text { Complete } \\
\text { Initial Resection }\end{array}$ & $\begin{array}{c}\text { Incomplete- } \\
\text { Initial Resection }\end{array}$ \\
good & 12 & 5 \\
fair & 10 & 3 \\
poor & 2 & 2 \\
recurrence & $\frac{2}{3}$ \\
\hline
\end{tabular}

$\sim$ includes case in which degree of resection was uncertain at first surgery.

There have been two tumour recurrences in patients who were considered to have had complete resections. One tumour recurred 2 years after initial resection and the patient is now well 2 years after the second operation with no clinical or CT evidence of recurrence. This tumour had initially extended through the tentorial hiatus and subsequently recurred along the petrous ridge. The recurrence was removed via a subtemporal approach. The second patient who presented with a $1.5 \mathrm{~cm}$ petrous apex meningioma recurred 4 years after initial resection. The tumour was discovered growing en plaque along the medial petrous ridge. The patient suffered a postoperative hemorrhage into the tumour bed to which she succumbed despite emergency evacuation of the clot.

A patient died 9 years after resection of a large meningioma which arose lateral to the porus acousticus when the peritoneal end of her ventriculoperitoneal shunt perforated the cecum resulting in a fatal brain abscess at the site of tumour resection. There was no evidence of recurrent tumour at autopsy.

Four tumours were incompletely resected, two of whom have undergone repeat operations because of progression (Table 3 ). One patient, who had a moderate sized tumour with tentorial extension, developed progressive brain stem compression 3 years after incomplete resection. A repeat attempt at tumour decompression resulted in a fatal brainstem stroke. The other patient presented initially with a middle ear mass which proved to be an extension from a large petrous meningioma. This was incompletely excised by a subtemporal approach and 7 years later by a staged suboccipital and subtemporal approach. The patient is now well 2 years after this resection with $\mathrm{CT}$ evidence of tumour. Two clinically well elderly patients are being followed with CT scan proven residual tumours 6 months and 4 years after incomplete resections.

We were unable to determine the extent of the first resection in one case. This patient underwent a second resection 6 years later which was felt to be incomplete although the patient had no evidence of recurrence clinically or on CT scan 3 years after the second operation.

\section{Discussion}

Meningiomas arising in the posterior cranial fossa are uncommon lesions, constituting 8-12\% of intracranial meningiomas and $7-12 \%$ of all posterior fossa tumours. $1,9,6$ 
Castellano and Ruggierol divide posterior fossa meningiomas into five groups based on the dural site of attachment as follows: those arising from the cerebellar convexity, tentorium, posterior surface of the petrous bone, clivus and foramen magnum. Meningiomas arising from the posterior surface of the petrous bone account for $42 \%$ of the posterior fossa meningiomas. 1 Clusters of arachnoid cap cells concentrate around cranial nerve foramina and dural venous sinuses which are common sites of origin of petrous meningiomas. ${ }^{10,1,6}$ Of the petrous meningiomas, Castellano and Ruggierrol found the most common site of origin in their 30 cases to be medial to the internal auditory meatus in the area of the superior petrosal sinus. In contrast Yasargil, et al 6 found that $50 \%$ of petrous meningiomas arose between the internal auditory meatus and jugular foramen. The most common site was at or medial to the porus in the present series. Operative morbidity and mortality are higher with more medially placed tumours $1.11 .3,6$ and recurrence rates may also be different depending on the dural site of attachment.2.13,14

Clinical differentiation between meningioma and acoustic neuroma may be difficult. Symptomatic trigeminal neuralgia especially if it precedes the development of hearing loss and early involvement of the facial nerve suggest meningioma. ${ }^{15.16,6 \mathrm{~A}}$ large CPA mass and relatively preserved hearing is more likely to be meningioma than acoustic neuroma. 15 -18 Plain skull film and petrous bone tomographic abnormalities, which may include changes of intracranial hypertension, tumour calcification, alteration of the porus acousticus and erosion or hyperostosis of the petrous bone, were found in only a few of our patients, as has been the experience in most reported series. 19,20,11,21

Enhanced axial CT scanning with thin cuts supplemented with direct coronal imaging in selected cases was our most useful diagnostic test. The typical CT features of petrous meningiomas which help in differentiation from acoustic neuromas include hyperdensity on plain CT, intratumoural calcification, homogeneous intense enhancement, broad dural base, oval shape, a normal porus acousticus and extension anteriorly onto the clivus or superiorly through the tentorial hiatus. ${ }^{16.22 .21}$ There is usually surrounding low density edema. Cerebral angiography provides important information about vessel displacement and lesion vascularity in patients with CPA masses. The classic venous and arterial changes caused by CPA masses are well known. ${ }^{20,23}$

There are several approaches to the CPA.24.18.8.11.5.6 The most commonly employed approach to these tumours is the lateral suboccipital or retromastoid technique. This exposure provides the shortest route to the tumour as well as early identification of the lower cranial nerves and major vessels. Other advantages include the ease with which CSF may be drained from the basal cisterns to facilitate cerebellar retraction and the ability to readily preserve hearing and facial nerve function.

The advantages of the various translabyrinthine approaches which have been developed for acoustic neuroma surgery are negated when one suspects a meningioma preoperatively. ${ }^{24.8}$ An attempt at hearing preservation is often indicated for such patients and one rarely encounters a deaf patient harboring a suitably sized meningioma. As well, intracanalicular extension is of lesser concern with CPA meningiomas.

A frontotemporal trans-Sylvian approach to the posterior fossa was developed by Yasargil.25.6 Our experience with this approach is limited; however, the exposure appears difficult. The resection of a middle fossa component and the superior portion of the posterior fossa component of the tumour with direct visualization of the upper cranial nerves may be carried out by this approach.

Exposure of petrous meningiomas through a subtemporal craniotomy with elevation of the temporal lobe and occasionally division of the tentorium may be useful.5.6 This technique allows removal of the middle fossa component of these tumours at less depth than the frontotemporal trans-Sylvian approach. We used this method in three cases either as a planned two stage resection or in approaching recurrent tumours which had extended into the middle fossa.

Operative mortality in several series of CPA meningiomas has ranged from 0 to $40 \% .1 .9,19,2.11,4,5.6$ Complete resections were often obtained in less than $50 \%$ of cases. 5.6 We were able to completely excise the tumour in 12 cases with no operative mortality, similar to the results reported by Sekhar and Jannetta. 5

Tumour recurrence has been infrequently reported; however, tumour recurrence may be more frequently anticipated with long term follow-up. ${ }^{5}$ Potential causes of recurrence include unrecognized dural sinus, bone or brain invasion, spread of tumour en plaque in the subdural space and regional multicentricity. 26,14 Both patients in our series who recurred after presumed complete resection did so within 5 years and had tumour subsequently arising along the petrous ridge extending into the middle fossa.

Morbidity after resection of petrous meningiomas involves worsening of cranial nerve function. We report permanent worsening of at least one cranial nerve in nine patients. However, when considering the size of these tumours, preservation of the vestibulocochlear and facial nerves in much more likely when the diagnosis is meningioma. $27,25.6$

Inability to completely resect these tumours was encountered in four cases in our series, similar to the experience of Sekhar and Jannetta. ${ }^{5}$ The reasons for incomplete resection include clival or tentorial extension and extradural skull base invasion. ${ }^{11.5}$

Radiation therapy has been employed in the management of incompletely resected and malignant meningiomas in the supratentorial compartment; but experience in its use in the posterior fossa is very limited. 28.29

In summary, curative complete resection can now be obtained in many patients with petrous meningiomas with minimal mortality and morbidity. However, the resection of these tumours remains a formidable undertaking. Postoperative worsening or cranial nerve function and tumour recurrence because of incomplete tumour resection are the main difficulties. Modern electrophysiologic monitoring may help to reduce the cranial nerve injury. Our recommendation is that an aggressive initial approach be taken with the goal of complete tumour resection where possible. Dural coagulation in the region of the petrous apex, medial tentorial edge, superior petrosal sinus and site of tumour dural attachment may aid in the prevention of tumour recurrence.

\section{ACKNOWLEDGEMENT}

The authors wish to thank Dina Evans and Carolyn Smith for their clerical assistance in the preparation of this manuscript. 


\section{REFERENCES}

1. Castellano F, Ruggiero G. Meningiomas of the posterior fossa. Acta Radiol (Suppl) 1953; 104: 1-177.

2. Markham JW, Fager CA, Horrax G, et al. Meningiomas of the posterior fossa. Their diagnosis, clinical features, and surgical treatment. Arch Neurol Psychiatry 1955; 74: 163-170.

3. Russell JR, Bucy PC. Meningiomas of the posterior fossa. Surg Gynecol Obstet 1953; 96: 183-192.

4. Scott M. The surgical management of meningiomas of the cerebellar fossa. Surg Gynecol Obstet 1972; 135: 545-550.

5. Sekhar LN, Jannetta PJ. Cerebellopontine angle meningiomas. Microsurgical excision and follow-up results. J Neurosurg 1984; 60: 500-505.

6. Yasargil MG, Mortara RW, Curcic M. Meningiomas of the basal posterior cranial fossa. In: Krayenbuhl $\mathrm{H}$, ed. Advances and technical standards in Neurosurgery. Wien: Springer-Verlag 1980, vol. 7: 3-115.

7. Harner SG, Ebersold MJ. Management of acoustic neuromas.19781983. J Neurosurg 1985, 63: 175-179.

8. King TT, Morrison AW. Translabyrinthine and transtentorial removal of acoustic nerve tumours. Results in 150 cases. J Neurosurg 1980; 52: 210-216.

9. Cushing H, Eisenhardt L. Meningiomas: their classification, regional behavioral, life history, and surgical end results. Springfield III: Charles C Thomas 1938; 785.

10. Aoyogi T, Kyuno K. Uber die Endothelialen zellzapfen in der dura mater cerebri und ihr lokalisation in derselben, nebst ihrer beziehung zur geschwulstbildung in der dura mater. Neurologia 1912; 11: 1-12.

11. Mayberg MR, Symon L. Meningiomas of the clivus and apical petrous bone. Report of 35 cases. J Neurosurg 1986; 65: 160167.

12. Chan RC, Thompson GB. Morbidity, mortality and quality of life following surgery for intracranial meningiomas. A retrospective study in 257 cases. J Neurosurg 1984; 60: 52-60.

13. Mirimanoff RO, Dosoretz DE, Linggood RM, et al. Meningioma: analysis of recurrence and progression following neurosurgical resection. J. Neurosurg 1985; 62: 18-24.

14. Simpson D. The recurrence of intracranial meningiomas after surgical treatment. J Neurol Neurosurg Psychiatry 1957; 20: 22-39.
15. Brown HA, Love JG. Significance of otologic findings in cerebellopontine meningioma. Laryngoscope 1956; 66: 1186-1201.

16. Catz A, Reider-Groswasser I. Acoustic neurinoma and posterior fossa meningioma - clinical and CT radiologic findings. Neuroradiology 1986, 28: 47-52.

17. Granick MS, Martuza RL, Parker SW, et al. Cerebellopontine angle meningiomas: clinical manifestations and diagnosis. Ann Otol Rhinol Laryngol 1985; 94: 34-38.

18. Hart RG, Davenport J. Diagnosis of Acoustic Neuroma. Neurosurgery 1981; 9: 450-463.

19. Grand W, Bakay L. Posterior fossa meningiomas. A report of 30 cases. Acta Neurochir 1975; 32: 219-233.

20. Kendall B, Symon L. Investigation of patients presenting with cerebellopontine angle syndromes. Neuroradiology 1977; 13:65-84.

21. Moller A, Hatam A, Olivecrona $\mathrm{H}$. The differential diagnosis of pontine angle meningioma and acoustic neuroma with computed Iomography. Neuroradiology 1978; 17: 21-23.

22. Dubois P. Tumours of the cerebellopontine angle: Radiology. $\mathrm{Im}$ : Wilkins RH, Rengachary SS, eds. Neurosurgery. New York: McGraw Hill 1985; 704-719.

23. Salamon GM, Combalbert A, Raybaud $C$, et al. An angiographic study of meningiomas of the posterior fossa. J Neurosurg 1971; 35: 731-74l.

24. Gianotta SL, Pulee JL, Goodkin R. Translabyrinthine removal of cerebellopontine angle meningiomas. Neurosurgery 1985; 17: 620-625.

25. Yasargil MG, Smith RD, Gasser JC. Microsurgical approach to acoustic neurinomas, in Krayenbuhl $\mathrm{H}$, ed. Advances and technical standards in neurosurgery. Wien/New York: Springer-Verlag 1977; vol. 4: 93-129.

26. Borovich B. Doron Y. Recurrence of intracranial meningiomas: the role played by regional multicentricity. J Neurosurg 1986; 64: 58-63.

27. Tator $\mathrm{CH}$, Nedzelski JM. Preservation of hearing in patients undergoing excision of acoustic neuromas and other cerebellopontine angle tumors. J Neurosurg 1985; 63: 168-174.

28. Carella RJ, Ransohoff J, Newall J. Role of radiation therapy in the management of meningioma. Neurosurgery 1982: 10: 332-339.

29. Wara WM, Sheline GE, Newman $\mathrm{H}$, et al. Radiation therapy of meningiomas. AJR 1975; 123: 453-458. 